\title{
PENINGKATAN KEMAMPUAN KOGNITIF ANAK MELALUI PENERAPAN METODE EKSPERIMEN DALAM PEMBELAJARAN SAINS PADA ANAK
}

\author{
Intan Martha Fidiyani, Ali Nugraha, Rita Mariyana \\ Universitas Pendidikan Indonesia, Jln. Setiabudhi no. 229 Bandung
}

\begin{abstract}
Improved Child cognitive ability through application of Experimental Methods in Learning Science Kids ON. Purpose Of Research Singer is implementing the Learning WITH using experimental method / Attempted to review improve cognitive abilities Children in kindergarten. Kartini Village Jatitengah Jatitujuh District of Majalengka. Used operates Namely Research Action Research (PTK) that includes cognitive development Namely ASPECTS OF ASSESSMENT 1). Know And Mixing Colors, 2). Know the Cause and Effect Occurrence Rain, 3). Know the Differences Rough and Smooth, 4). Imitating the Pattern, 5). Develop Pieces of Puzzle. The subject of research is the Son of group B TK. Kartini Village Jatitengah Jatitujuh District of Majalengka in the academic year 2014-2015 That amounts to 39 Children. Based on the findings that the application of the experimental method, observation / experiment to improve cognitive abilities Children's review showed Developments That Are Very Good. It Singer visible from EVERY improvement cycle, including CYCLE I 18.97\% Children Not Evolve (BB) 72.82 Children From Growing (MB), 8.20\% Emerging accordance Hope Kids, Kids and 0\% Emerging Very Good (BSB ). TIN average value of 1.9 and mastery learning reached $47.24 \%$. THE CYCLE II increased $1.54 \%$ including Son Not Yet Evolving (BB), 41.74\% Start Child Development (MB), 41.54\% Emerging accordance Children Hope (BSH), 11.28\% Children Growing Very Good ( BSB) The value of the average TIN mastery learning by 2.56 and reached $64.49 \%$ and the ON CYCLE III Namely increased The Very encouraging Ie $0 \%$ Children Not Evolve (BB), $0.51 \%$ Start Child Development (MB) $46.67 \%$ Emerging accordance Children Hope (BSH) and 52.82\% of Children growing Very Good (BSB) averaged TIN value of 3.5 and mastery learning reached $87.44 \%$. Based on the research findings of CAN concluded that the application of the experimental method CAN improve cognitive abilities of the Child. Recommendations Of Research Singer is professor CAN hearts experimental method using learning activities in kindergarten.
\end{abstract}

Keywords: cognitive ability children, experimental methods, science learning.

\begin{abstract}
Abstrak: Peningkatan Kemampuan Kognitif Anak Melalui Penerapan Metode Eksperimen Dalam Pembelajaran Sains Pada Anak. Tujuan dari penelitian ini adalah melaksanakan pembelajaran dengan menggunakan metode eksperimen/percobaan untuk meningkatkan kemampuan kognitif anak di TK. Kartini Desa Jatitengah Kecamatan Jatitujuh Kabupaten Majalengka. Jenis penelitian yang digunakan yaitu Peneletian Tindakan Kelas (PTK) yang mencakup aspek penilaian pengembangan kognitif yaitu 1). Mengenal dan Mencampur Warna, 2). Mengenal Sebab Akibat Terjadinya Hujan, 3). Mengenal Perbedaan Kasar dan Halus, 4). Meniru Pola, 5). Menyusun Kepingan Puzzle. Adapun subjek penelitian adalah anak kelompok B TK. Kartini Desa Jatitengah Kecamatan Jatitujuh Kabupaten Majalengka tahun pelajaran 2014-2015 yang berjumlah 39 anak. Berdasarkan hasil observasi bahwa penerapan metode eksperimen/percobaan untuk meningkatkan kemampuan kognitif anak menunjukan perkembangan yang sangat baik. Hal ini terlihat dari peningkatan setiap siklusnya, diantaranya siklus I 18,97\% anak Belum Berkembang
\end{abstract}


(BB), 72,82 anak Mulai Berkembang (MB), 8,20\% anak Berkembang Sesuai Harapan, dan $0 \%$ anak Berkembang Sangat Baik (BSB). nilai rata-ratanya diperoleh sebesar 1,9 dan ketuntasan belajarnya mencapai $47,24 \%$. Pada siklus II mengalami peningkatan diantaranya 1,54\% anak yang Belum Berkembang (BB), 41,74\% anak Mulai Berkembang (MB), 41,54\% anak Berkembang Sesuai Harapan (BSH), 11,28\% anak Berkembang Sangat Baik (BSB) nilai rata-ratanya diperoleh sebesar 2,56 dan ketuntasan belajarnya mencapai $64,49 \%$ dan pada siklus III yaitu mengalami peningkatan yang sangat mengembirakan yaitu $0 \%$ anak Belum Berkembang (BB), 0,51\% anak mulai Berkembang (MB), 46,67\% anak Berkembang Sesuai Harapan (BSH) dan 52,82\% anak yang Berkembang Sangat Baik (BSB) nilai rata-ratanya diperoleh sebesar 3,5 dan ketuntasan belajarnya mencapai 87,44\%. Berdasarkan hasil penelitian dapat disimpulkan bahwa penerapan metode eksperimen dapat meningkatkan kemampuan kognitif anak. Rekomendasi dari penelitian ini adalah guru dapat menggunakan metode eksperimen dalam kegiatan pembelajaran di TK.

Kata Kunci : kemampuan kognitif anak, metode eksperimen, pembelajaran sains.

Sujiono, dkk (2007, hlm. 14) beberapa ahli psikologi yang berkecimpung dalam bidang pendidikan mengidentifikasikan intelektual atau kognitif dengan berbagai peristilahan, diantaranya : 1). Terman mengidentifikasikan bahwa kognitif adalah kemampuan untuk berpikir secara abstrak; 2). Colvin mengidentifikasikan bahwa kognitif adalah kemampuan untuk menyesuaikan diri dengan lingkungan; 3). Henman mengidentifikasikan bahwa kognitif adalah intelektual ditambah dengan pengetauan; 4). Hunt mengidentifikasikan bahwa kognitif adalah teknik untuk memproses informasi yang disediakan oleh indra.

Menanggapi pendapat para ahli di atas, bahwa definisi kognitif banyak macam ragam yang dikemukakan oleh para ahli, namun pada prinsipnya bahwa kognitif adalah intelegensi atau cara berfikir seseorang untuk dapat mampu memecahkan masalah atau menciptakan sebuah hasil karya.

Guru Taman Kanak-Kanak (TK) dalam melaksanakan kegiatan Proses Belajar Mengajar (PBM) nya dituntut untuk lebih enerjik dalam merangsang dan mengembangkan aktivitas dan kreativitas anak agar timbulnya kreasi dan daya pikir anak lebih berkembang. Hal itu sesuai dengan

pendapat Sujiono (2007, hlm. 1.9) ...pendidikan seharusnya membantu anak untuk menemukan harta kreativitas yang tersembunyi dalam dirinya dan membantu dia sungguh-sungguh mampu menyatakan dan memunculkan kreativitas itu.

Untuk melatih kognitif atau
intelegensi anak-anak berkembang, maka perlu adanya tindakan nyata dari guru Taman Kanak-Kanak (TK) dalam melaksanakan kegiatan proses pembelajaran sehingga terjadinya komunikasi timbal balik antara guru dengan anak, dan anak dengan gurunya.

Dengan demikian, dikarenakan pendidkan di Taman Kanak-Kanak (TK) merupakan pendidikan awal/pra sekolah yang sangat menentukan untuk kehidupan anak dimasa yang akan datang baik secara fisik maupun psikis agar anak dapat beraktivitas dan bersosialisasi dalam kehidupan bermasyarakat dimasa yang akan datang. 


\section{METODE}

Metode penelitian yang digunakan dalam penelitian ini adalah metode Penelitian Tindakan Kelas, sebagaimana di ungkapkan oleh Wihardhit dan Wardhanni (2008:1.3) penelitian tindakan kelas merupakan satu penelitian pula, yang dengan sendirinya mempunyai berbagai aturan dan langkah yang harus diikuti. Penelitian tindakan kelas terjemahan dari Clasroom Action Research, yaitu satu Action Research yang dilakukan di kelas.

\section{Menurut Mulyana}

$(2008: 154)$ mengungkapkan bahwa "penelitian tindakan kelas ini merupakan suatu cara memperbaikai dan meningkatkan profesionalisme guru, karena guru merupakan orang yang paling tahu mengenai segala sesuatu yang terjadi dalam pembelajaran". Hal itu sesuai dengan pendapat Wihardhit dan Wardhani (2008:1.4) "Penelitian tindakan kelas adalah penelitian yang dilakukan oleh guru di dalam kelasnya sendiri melalui refleksi diri, dengan tujuan untuk memperbaiki kinerjanya sebagai guru, sehingga hasil belajar siswa menjadi meningkat".

\section{HASIL DAN PEMBAHASAN}

\section{Kondisi Objektif Kemampuan Kognitif Anak Sebelum Penerapan Metode Eksperimen di TK Kartini}

Sebelum dilaksanakan kegiatan tindakan proses pembelajaran siklus I, II, dan III terlebih dahulu peneliti melaksanakan kegiatan pra siklus dengan maksud dan tujuan untuk mendapat gambaran kondisi objektif kemampuan kognitif anak Taman Kanak-Kanak (TK) Kartini. Kegiatan pra siklus dilaksanakan pada hari Senin, Selasa, Rabu Tgl 2, 3, dan 4
Mei 2015 dengan hasil observasi pengamatan dan penilaian kegiatan pra siklus dapat dilihat pada tabel sebagai berikut:

\section{Tabel 1.3 Hasil Penilaian Penerapan Metode Eksperimen/Percobaan Untuk Peningkatan Kemampuan Kognitif Anak Pra Siklus}

\begin{tabular}{|c|c|c|c|c|c|c|}
\hline \multirow{2}{*}{ No. } & \multirow{2}{*}{$\begin{array}{l}\text { Nama } \\
\text { Anak }\end{array}$} & \multicolumn{5}{|c|}{ Aspek yang dinilai } \\
\hline & & 1. & 2. & 3. & 4. & 5. \\
\hline 1. & A V & 2 & 2 & 2 & 2 & 1 \\
\hline 2. & AMQU & 2 & 3 & 2 & 2 & 1 \\
\hline 3. & RKS & 1 & 2 & 2 & 1 & 1 \\
\hline 4. & RA & 2 & 3 & 2 & 2 & 2 \\
\hline 5. & ASP & 1 & 2 & 2 & 1 & 1 \\
\hline 6. & AAZ & 2 & 3 & 2 & 2 & 2 \\
\hline 7. & AFK & 2 & 2 & 2 & 2 & 2 \\
\hline 8. & CTNH & 1 & 1 & 1 & 1 & 1 \\
\hline 9. & CAS & 2 & 1 & 1 & 1 & 1 \\
\hline 10. & GLS & 1 & 2 & 2 & 2 & 1 \\
\hline 11. & ATL & 1 & 2 & 1 & 1 & 1 \\
\hline 12. & AFR & 2 & 3 & 2 & 2 & 2 \\
\hline 13. & GS & 2 & 1 & 1 & 2 & 1 \\
\hline 14. & HD & 1 & 2 & 2 & 2 & 1 \\
\hline 15. & ID & 2 & 3 & 2 & 2 & 1 \\
\hline 16. & $\mathrm{~J}$ & 1 & 2 & 2 & 1 & 1 \\
\hline 17. & KNM & 2 & 3 & 2 & 2 & 1 \\
\hline 18. & MAJ & 2 & 3 & 2 & 2 & 2 \\
\hline 19. & MFN & 1 & 1 & 1 & 1 & 1 \\
\hline 20. & $\mathrm{~N}$ & 1 & 2 & 2 & 2 & 1 \\
\hline 21. & $\mathrm{RM}$ & 2 & 3 & 2 & 2 & 2 \\
\hline 22. & RFI & 1 & 1 & 2 & 2 & 1 \\
\hline
\end{tabular}




\begin{tabular}{|c|c|c|c|c|c|c|}
\hline 23. & MRA & 2 & 1 & 2 & 1 & 1 \\
\hline 24. & NY & 2 & 3 & 2 & 2 & 2 \\
\hline 25. & NHK & 2 & 2 & 2 & 2 & 1 \\
\hline 26. & RGW & 1 & 1 & 1 & 1 & 1 \\
\hline 27. & RAM & 1 & 1 & 1 & 1 & 1 \\
\hline 28. & $\mathrm{RM}$ & 2 & 1 & 2 & 1 & 1 \\
\hline 29. & $\mathrm{RM}$ & 2 & 1 & 1 & 1 & 1 \\
\hline 30. & RMF & 2 & 1 & 1 & 2 & 1 \\
\hline 31. & SS & 2 & 2 & 2 & 2 & 2 \\
\hline 32. & SK & 2 & 1 & 2 & 2 & 1 \\
\hline 33 & SO & 2 & 2 & 2 & 2 & 2 \\
\hline 34. & SR & 2 & 2 & 2 & 2 & 1 \\
\hline 35. & WF & 2 & 1 & 2 & 2 & 1 \\
\hline 36. & $\mathrm{NNH}$ & 1 & 1 & 1 & 1 & 1 \\
\hline 37. & VAM & 2 & 2 & 2 & 2 & 1 \\
\hline 38. & MRAA & 2 & 3 & 2 & 2 & 2 \\
\hline 39. & $\mathrm{ZN}$ & 2 & 2 & 2 & 2 & 1 \\
\hline \multicolumn{2}{|c|}{ Jumlah Scor } & 66 & 74 & 68 & 65 & 49 \\
\hline \multicolumn{2}{|c|}{$\begin{array}{l}\text { Nilai } \\
\text { Ketercapaian } \\
\text { Rata-rata. }\end{array}$} & 1,69 & 1,90 & 1,74 & 1,67 & 1,26 \\
\hline \multicolumn{2}{|c|}{$\begin{array}{l}\text { Nilai } \\
\text { Ketuntasan } \\
\text { Hasil Belajar }\end{array}$} & $\begin{array}{c}42,3 \\
1 \%\end{array}$ & $\begin{array}{c}47,4 \\
4 \%\end{array}$ & $\begin{array}{c}43,5 \\
9 \%\end{array}$ & $\begin{array}{c}41,6 \\
7 \%\end{array}$ & $\begin{array}{c}31,4 \\
1 \%\end{array}$ \\
\hline
\end{tabular}

\section{Penerapan Metode Eksperimen dalam Meningkatkan Kognitif Anak di TK. Kartini}

Kegiatan tindakan proses pembelajaran penerapan metode eksperimen/ percobaan untuk meningkatkan kemampuan kognitif anak pada usia dini Taman Kanak-Kanak (TK) Kartini dilaksanakan dalam satu tindakan pembelajaran dan satu kali tindakan evaluasi pembelajaran yang telah dipersiapkan dalam kegiatan yang terdiri dari siklus I, siklus II dan siklus III.

Kegiatan proses pembelajaran penerapan metode eksperimen/percobaan untuk meningkatkan kemampuan kognitif anak usia dini Taman Kanak-Kanak (TK) Kartini Deasa Jatitengah Kecamatan Jatitujuh Kabupaten Majalengka dilaksanakan oleh peneliti sebanyak 3 (tiga) siklus atau tindakan. Pelaksanaannya diawali dengan pembukaan kegiatan metode eksperimen/percobaan dengan memotivasi belajar anak, mengadakan apersepsi, dan menyampaikan tujuan pembelajaran yang hendak dicapai.

\section{Peningkatan Kemampuan Kognitif Anak Setelah Penerapan Metode Eksperimen di TK. Kartini}

Berdasarkan hasil observasi, pengamatan dan penilaian pada kegiatan pra siklus dan tindakan proses pembelajaran yang dilaksanakan siklus I, II, dan III membuktikan bahwa penerapan metode eksperimen/percobaan dalam pembelajaran sains dapat meningkatkan kemampuan kognitif anak pada anak usia dini di Taman Kanak-Kanak (TK) Kartini Desa Jatitengah Kecamatan Jatitujuh Kabupaten Majalengka. Peningkatan tersebut tidak terlepas dari datadata hasil kegiatan pra siklus maupun hasil observasi, pengamatan dan peniliaian pada tindakan siklus I, II dan III.

Masa peka memiliki arti penting bagi perkembangan setiap anak. Peingkatan kemampuan kognitif tersebut berpengaruh terhadap ketercapaian nilai rata-rata dan ketuntasan belajar anak, misalnya kegiatan pra siklus ketercapaian nilai rata-ratanya 1,65 dan ketuntasan belajarnya 41,28\%. Pada kegiatan tindakan pembelajaran siklus I mengalami peningkatan yaitu ketercapaian nilai rata-ratanya 1,9 dan ketuntasan 
belajarnya mencapai 47,31\%. Begitu juga peningkatan di kegiatan tindakan pembelajaran siklus II yaitu ketercapaian nilai rata-ratanya 2,53 dan ketuntasan belajarnya mencapai $63,41 \%$, dan pada kegiatan tindakan pembelajaran siklus III ketercapaian nilai rata-ratanya 3,5 dan ketuntasan belajarnya $87,44 \%$. Hal itu dapat dilihat pada grafik dibawah ini.

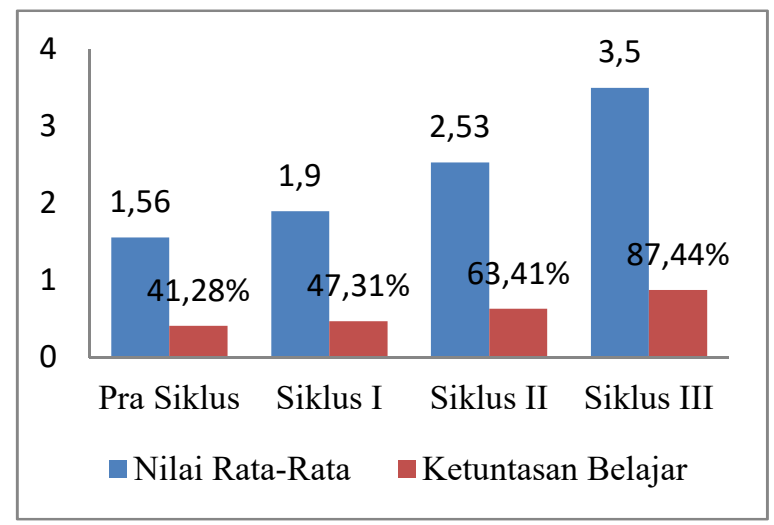

Grafik 1.3 Nilai Rata-Rata dan Ketuntasan Belajar Kemampuan Kognitif Anak Pra Siklus, Siklus I, Siklus II, dan Siklus III

\section{Kondisi Objektif Kemampuan Kognitif Anak Sebelum Penerapan Metode Eksperimen di TK. Kartini}

Sebelum dilaksanakannya penelitian tentang peningkatan kemampuan kognitif anak melalui penerapan metode eksperimen dalam pembelajaran sains, kemampuan kognitif anak TK. Kartini dirasakannya belum adanya perkembangan yang signifikan, karena berdasarkan hasil observasi, pengamatan dan penilaian terhadap kegiatan pra siklus tentang kemampuan kognitif anak yang menyangkut aspek penilaian mengenal dan mencampur warna, mengenal sebab akibat terjadinya hujan, mengenal perbedaan kasar dan halus, meniru pola dan menyusun kepingan puzle belum menunjukkan kemampuan kognitif anak yang berarti.

Menurut hasil obervasi, pengamatan dan penilaian sebelum dilaksanakannya penelitian tentang kemampuan kognitif anak TK. Kartini Desa Jatitengah Kecamatam Jatitujuh Kabupaten Majalengka menghasilkan data-data sebagai berikut:

Anak yang termasuk Belum Berkembang (BB) $40,71 \%$, anak yang termasuk Mulai Berkembang (MB) 54,56\%, anak yang Berkembang Sesuai Harapan (BSH) 5,13\%, dan anak yang belum Berkembang Sangat Baik (BSB) 0,00\%. Menurut data hasil kegiatan pra siklus tersebut, bahwa anak TK. Kartini Desa Jatitengah Kecamatam Jatitujuh Kabupaten Majalengka sangat dominan berada pada aspek perkembang belum berkembang dan mulai berkembang.

\section{Penerapan Metode Eksperimen dalam Meningkatkan Kemampuan Kognitif Anak di TK Kartini}

Penerapan metode eksperimen dalam meningkatkan kemampuan kognitif anak di Taman Kanak-Kanak (TK) Kartini Desa Jatitengah Kecamatan Jatitujuh Kabupaten Majalengka tidak terlepas dari kaidah-kaidah dalam pelaksanaannya, dengan maksud dan tujuan agar dapat mengekplorasi aktivitas dan pengetahuan anak melalui praktek langsung karena kegiatan eksplorasi memungkingkan anak dapat terlibat langsung dalam memberi keputusan. Hal ini sesuai dengan yang dijelaskan oleh Tylor (1990) dalam Masitoh (2007:7.18) kegiatan eksplorasi memungkinkan anak untuk mengembangkan penyelidikan langsung memalalui langkah-langkah spontan belajar membuat keputusan tentang apa yang dilakukan, bagaimana cara melakukanya, dan kapan melakukanya. Melalui kegiatan 
eksploratori anak-anak menemukan sesuatu yang berhubungan dengan dirinya sendiri dan memilih kegiatan yang sesuai dengan minatnya.

\section{Peningkatan Kemampuan Kognitif Anak Setelah Penerapan Metode Eksperimen di TK. Kartini}

Berdasarkan data hasil observasi, pengamatan dan penilaian terhadap pelaksanaan kegiatan pra siklus dan tindakan proses pembelajaran baik siklus I, II dan III setelah dilakukannya penerapan metode eksperimen/percobaan untuk meningkatkan kemampuan kognitif anak hasilnya cukup menggembirakan dan memuaskan, karena peneliti dalam melaksanakan tindakan proses pembelajaran sesuai dengan rencana yang telah dibuat sehingga berdampak terhadap meningkatnya perolehan nilai pada setiap aspek penilaian perkembangan kemampuan kognitif anak.

Hal itu sesuai dengan pendapat Mulyana (2008:154) menjelaskan bahwa "penelitian tindakan kelas ini merupakan suatu cara memperbaiki dan meningkatkan profesionalisme guru, karena guru merupakan orang yang paling tahu mengenai segala sesuatu yang terjadi dalam pembelajaran".

\section{SIMPULAN}

Berdasarkan pembahasan yang telah dijabarkan pada bab sebelumnya, maka diambil kesimpulan sebagai berikut :

1. Kemampuan kognitif anak sebelum penelitian ini dilakukan masih belum berkembang. Hal itu dibuktikan melalui kegiatan pra siklus, sebanyak 40,71\% anak Belum Berkembang (BB), 54,56\% anak Mulai Berkembang, 5,13\% anak Berkembang Sesuai Harapan dan 0\% anak Berkembang Sangat Baik (BSB). Pada kegiatan observasi awal belum ada anak yang berkembang sangat baik (BSB), ketercapaian nilai rata-ratanya 1,65 dan ketuntasan belajarnya mencapai $41,28 \%$.

2. Penerapan metode eksperimen dalam meningkatkan kemampuan kognitif anak dilaksanakan 3 (tiga) siklus. Siklus I masih ditemukan kelemahan-kelemahan baik dari peneliti maupun anak. Siklus II berdasarkan hasil observasi selama melaksanakan tindakan proses pembelajaran berlangsung adanya peningkatan baik peneliti dalam melaksanakan tindakan maupun anakanak dalam melaksanakan tugas yang diberikan oleh peneliti. Siklus III berdasarkan hasil observasi peneliti sudah banyak memperlihatkan kemajuan dalam melaksanakan tindakan lebih baik terutama dalam memberikan bimbingan dan memotivasi pada anak sehingga anak dapat melaksanakan tugas yang diberikan oleh peneliti dan dikerjakan oleh anak lebih baik.

3. Hasil penelitian yang dilaksanakan menunjukkan peningkatan yang cukup berarti baik kinerja peneliti maupun hasil perkembangan anak. Hasil observasi, pengamatan dan penilaian menunjukan peningkatan yang memuaskan. Berdasarkan hasil observasi pada tindakan siklus I 18,97\% anak Belum Berkembang (BB), 72,82 anak Mulai Berkembang (MB), 8,20\% anak Berkembang Sesuai Harapan, dan 0\% anak Berkembang Sangat Baik (BSB). Pada tindakan siklus II mengalami peningkatan diantaranya $1,54 \%$ anak yang Belum Berkembang (BB), 41,74\% anak Mulai Berkembang (MB), 41,54\% anak Berkembang Sesuai Harapan (BSH), 11,28\% anak Berkembang 
Sangat Baik (BSB) dan nilai rata-ratanya sebesar 2,53 dan ketuntasan belajarnya mencapai 63,41\%. Hasil tindakan siklus III mengalami peningkatan yang sangat mengembirakan yaitu 0\% anak Belum Berkembang (BB), 0,51\% anak mulai Berkembang (MB), 46,67\% anak Berkembang Sesuai Harapan (BSH) dan $52,82 \%$ anak yang Berkembang Sangat Baik (BSB) dan nilai rata-ratanya diperoleh sebesar 3,5 dan ketuntasan belajarnya mencapai $87,44 \%$.

\section{DAFTAR PUSTAKA}

Masitoh, dkk (2007) Strategi Pembelajaran TK, Jakarta : Universitas Terbuka.

Sujiono, dkk. 2007. Metode Pengembangan Kognitif. Modul 1, Bandung: Universitas Terbuka.

Igak Wardhani dan Kuswaya Wihardit. 2008. Penelitian Tindakan Kelas. Jakarta: Penerbit Universitas Terbuka

Mulyana, Deddy. 2008. Metodologi Penelitian Kualitatif Paradigma Baru Ilmu Komunikasi dan Ilmu Sosial Lainya. Bandung: Penerbit PT Remaja Rosdakarya 